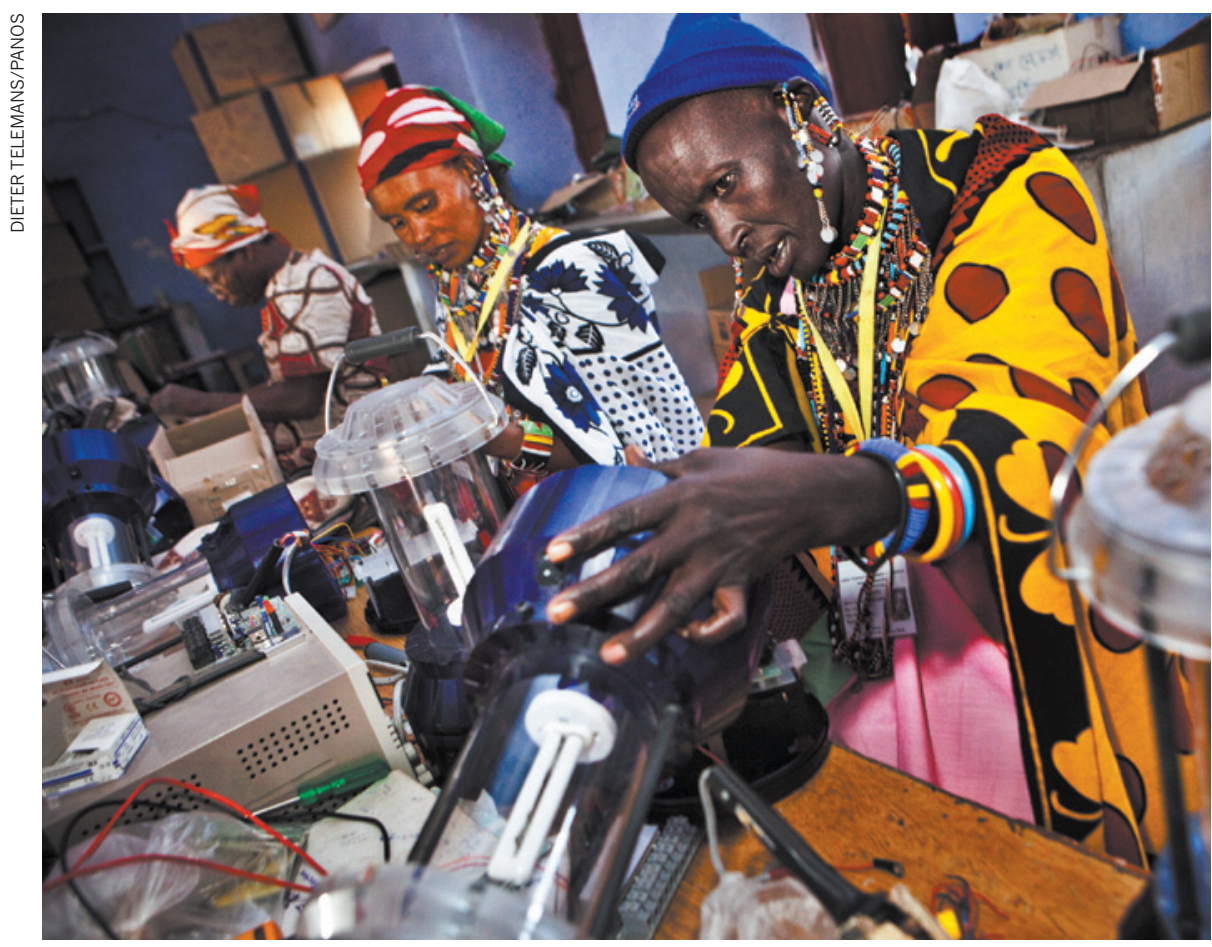

Masai women from Kenya take a course on solar energy in India.

\title{
Energy studies need social science
}

\section{A broader pool of expertise is needed to understand how human behaviour affects energy demand and the uptake of technologies, says Benjamin K. Sovacool.}

$\mathrm{T}$ o secure a safe, reliable and lowcarbon energy future, we must alter both technologies and human behaviour $^{1}$. The US Department of Energy notes ${ }^{2}$ that supply and demand is "affected as much by individual choice, preference, and behavior, as by technical performance".

Yet many researchers and policy-makers continue to focus on only one side of the energy dilemma. In the United States, for every dollar in research funds spent on behavioural and demand-side energy research, \$35 is spent on energy supply and infrastructure ${ }^{3}$. Social sciences, humanities, and the arts are marginalized in energy research, and major statistical agencies do not usually collect qualitative data about energy consumption. Similar problems are apparent in Europe ${ }^{4}$.

My analysis of the peer-reviewed energyresearch literature shows how biases handicap the field ${ }^{5}$. Engineers and economists are ignoring people and miscasting decisionmaking and action. Academic researchers frequently obsess over technical fixes rather than ways to alter lifestyles and social norms ${ }^{6}$. Interdisciplinary research remains stymied by institutional barriers in academia and government $^{7}$. National and local energy bodies have conventionally had few social scientists on staff $^{8}$. And most leading journals in the field focus on one discipline.

Now the energy field needs to learn from health, agriculture and business, and bring together social and physical scientists. Universities should develop courses focused on solving energy problems, granting agencies should prioritize and direct more money to behavioural work, and energy journals should broaden their scope. Already, there are promising examples of how inclusive and interdisciplinary energy research can encourage energy efficiency, and so address global environmental challenges such as climate change?

I examined the authorship and scope of 4,444 full-length articles over 15 years (1999 to 2013) in three leading energy technology and policy journals: Energy Policy and The Energy Journal have high impact factors, and The Electricity Journal was included to sample a regulatory journal. I found four worrisome trends: an undervaluation of the influence of social dimensions on energy use; a bias towards science, engineering and economics over other social sciences and the humanities; a lack of interdisciplinary collaboration; and the under-representation of female authors or those from minority groups.

For instance, technology adoption, the complexity of choice-making, and the human dimensions of energy use and environmental change were rarely covered (see 'Neglected topics'). Most articles (85\%) focused on advanced energy-production systems, such as nuclear reactors, sources of renewable electricity and biofuels, or the technical elements of electricity generation, transmission and distribution - hardware - rather than the human 'software' behind it. Simple devices such as cooking stoves, bicycles, light bulbs and distributed generation were studied in less than $3.5 \%$ of articles. Behaviour and energy demand was investigated in less than $2.2 \%$ of papers. If this work is being published, it is in environmental sociology, psychology and politicalscience journals that few energy researchers read.

\section{SOCIAL OUTCASTS}

Social-science authorship and citations are also relatively low (see 'Publishing trends'). Science, engineering, economics and statistics account for more than half (67\%) of institutional affiliations as reported by authors; non-economic social science for less than $20 \%$. Sociology, geography, history, psychology, communication studies and philosophy each constituted less than $0.3 \%$ of author affiliations.

References to social-science and humanities journals, with their insights into how consumers and politicians behave, were less than $4.3 \%$ of 90,097 citations across the sample. Little research took place in the 'real world'. Most studies are the result of work undertaken at the bench or desk using computer models and experiments, rather than field research, interviews and surveys.

Another trend is that the scientists and engineers writing in these journals rarely collaborate beyond their fields. About half of published authors in the sample wrote alone and one-quarter published with colleagues within their discipline. Less than $23 \%$ of articles involved interdisciplinary collaborations between authors.

Furthermore, the vast majority of authors hale from affluent Western institutions and countries where research money is abundant. They focus on problems facing the industrialized world. Of the 9,549 authors who listed their country of residence, $87 \%$ 
came from either North America or western Europe. African, Asian, Latin American and Middle Eastern authors were few. Authors were mostly male: only $15.7 \%$ could be identified as female. Norms of authorship and collaboration vary, but these trends held for each year examined: female authorship remained below $17.4 \%$ and non-Western authorship under $16 \%$, for example.

\section{FIVE RECOMMENDATIONS}

To bring in social scientists and other marginalized researchers, I have five recommendations.

First, public and private organizations should overhaul the way they structure and disburse funding for energy research and development. They should give a bigger slice to social scientists, improve incentives for interdisciplinary work and prioritize social topics in their funding calls - such as the perceptions of energy users, the needs of people affected by energy production and prevailing customs, traditions and behaviours.

Second, to reduce disciplinary bias, energy ministries, statistical agencies and public utility commissions should focus more on energy behaviour and demand, rather than just supply. Delaware and the District of Columbia, for instance, have sustainableenergy utilities, which advise residents about behavioural changes they can make to save energy and money. The statewide energyefficiency utility, Efficiency Vermont, provides funding and behavioural guidance to homes, farms and factories.

Third, administrators should make energy research more problem-oriented, including social perspectives as a matter of course. Universities should develop topical programmes on energy, as they have in agricultural research, medicine and business. Curricula might include efficient and sustainable consumption, risk management, public decision-making and the design of technologies for public acceptance and

\section{PUBLISHING TRENDS}

Social-science studies were rarely published in three leading energy journals from 1999 to 2013 . The emphasis on technology rather than human behaviour in energy research is reflected in the disciplinary backgrounds of authors, work referenced, and methods used.

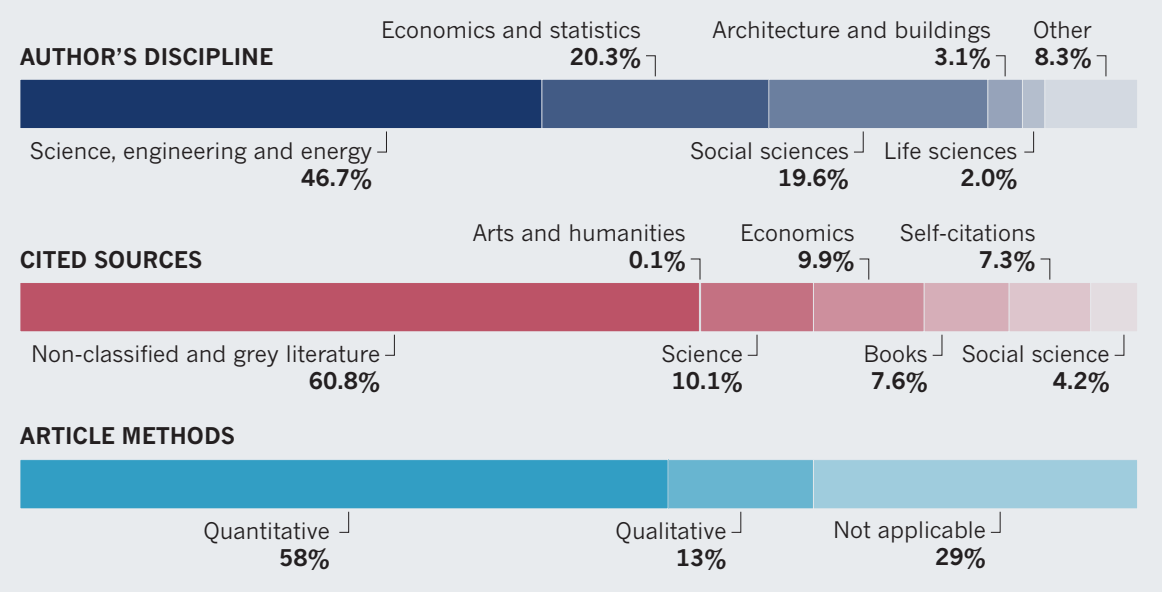

use. Good examples include the University of Edinburgh, UK, which offers an interdisciplinary master's degree in climate accounting; Aarhus University in Denmark has a business-development degree that combines engineering, innovation studies, energy studies, business and marketing; and Carnegie Mellon University in Pittsburgh, Pennsylvania, has an engineering and public policy department. Outside academia, the US Defense Advanced Research Projects Agency has successfully used a 'challengescentred' approach to national-security problems since it was created in 1958.

Fourth, researchers should do more to accommodate expertise and data from laypersons, indigenous groups, community leaders and other non-conventional participants. Although this may require special training to do effectively, such interactions would encourage greater feedback and integrate diverse viewpoints.

Fifth, journal editors can prioritize interdisciplinary, inclusive, comparative,

NEGLECTED TOPICS
Twelve subjects seldom considered in energy studies.
\begin{tabular}{l|l} 
Topic & Example \\
Gender and identity & Pollution from cooking stoves posing greater risk to women than men \\
\hline Philosophy and ethics & Future generations bearing the burden of pollution \\
\hline Communication and persuasion & Energy information changing individual or firm behaviour \\
\hline Geography and scale & Mismatching the size of energy systems to patterns of demand \\
\hline Social psychology and behaviour & Shaping energy choices by trust, control and denial \\
\hline Anthropology and culture & Temporal and regional differences in conceptions of energy services \\
\hline Research and innovation & How people, markets and institutions drive innovation \\
\hline Politics and political economy & Resources contributing to conflict or stymying growth \\
\hline Institutions and energy governance & Evolving rules and norms to address collective energy problems \\
\hline Energy and development & Energy use contributing to economic growth and falling poverty \\
\hline Externalities and pollution & Costs to society of erosions of environmental and ecological capital \\
\hline Sociology of technology & Economic, political and social drivers of energy consumption
\end{tabular}

mixed-methods research. A new journal published by Elsevier, Energy Research \& Social Science (of which I am editor-in-chief), calls explicitly in its aims and scope for papers that blend disciplinary concepts, go beyond single case studies, and utilize an assortment of methods. Wiley Interdisciplinary Reviews: Energy and Environment also seeks crossdisciplinary assessments of energy systems.

Energy studies must become more socially oriented, interdisciplinary and heterogeneous. Problem-focused research activities that centre on both physical and social processes, include diverse actors and mix qualitative and quantitative methods, have a better chance of achieving analytic excellence and social impact.

Benjamin K. Sovacool is professor of business and social sciences, and director of the Centre for Energy Technologies, at Aarhus University in Denmark. He is also associate professor of law at Vermont Law School in South Royalton, Vermont, USA, and editor-in-chief of Energy Research \& Social Science.

e-mail:sovacool@vt.edu

1. Dietz, T., Gardner, G.T., Gilligan, J., Stern, P. C. \& Vandenbergh, M. P. Proc. Natl Acad. Sci. USA 106 18452-18456 (2009).

2. US Department of Energy Report on the First Quadrennial Technology Review 125 (US Department of Energy, 2011).

3. Gaffigan, M. E. Advanced Energy Technologies: Budget Trends and Challenges for DOE's Energy R\&D Program (US Government Accountability Office, 2008).

4. Goldblatt, D. L. et al. (eds) Tackling Long-Term Global Energy Problems: The Contribution of Social Science (Springer, 2012).

5. Sovacool, B. K. Energy Res. Soc. Sci. 1, 1-29 (2014).

6. D'Agostino, A. L. et al. Energy 36, 508-519 (2011).

7. Lutzenhiser, L. \& Shove, E. Energy Policy 27, 217-227 (1999).

8. Stern, P. C. Science 260, 1897-1899 (1993)

9. Alcott, H. \& Mullainathan, S. Science $\mathbf{3 2 7}$, 1204-1205 (2010). 